\title{
In vivo wear of CAD-CAM composite versus lithium disilicate full coverage first-molar restorations: a pilot study over 2 years
}

\author{
Jan-Frederik Güth ${ }^{1} \cdot$ Kurt Erdelt $^{1} \cdot$ Christine Keul $^{1} \cdot$ Gintare Burian $^{1} \cdot$ Josef Schweiger $^{1} \cdot$ Daniel Edelhoff $^{1}$
}

Received: 19 August 2019 / Accepted: 17 April 2020 / Published online: 12 May 2020

(C) The Author(s) 2020

\begin{abstract}
Objectives To present a digital approach to measure and compare material wear behavior of antagonistic first molar restorations made of an experimental CAD/CAM composite (COMP) and lithium disilicate ceramic (LS2) in patients with reconstructed vertical dimension of occlusion (VDO) after generalized hard tissue loss.

Methods A total of 12 patients underwent complete full jaw rehabilitation with full occlusal coverage restorations made either of COMP or LS2. The first molar restorations $(n=48)$ were chosen for wear examination. At annual recall appointments, polyether impressions were taken, and resulting plaster casts were digitalized using a laboratory scanner. Mean observation period was 371 days for first and 769 days for second year. The resulting 96 datasets were analyzed by superimposition of 3-D datasets using an iterative best-fit method. Based on the superimposition data, the wear rates of the occlusal contact areas (OCAs) were calculated.

Results For antagonistic restorations made of COMP, the average wear rate was $24.8 \pm 13.3 \mu \mathrm{m} / \mathrm{month}$, while for LS2, it was 9.5 $\pm 4.3 \mu \mathrm{m} /$ month in first year, with significant differences $(p<0.0001)$ between the materials. In second year, monthly wear rates decreased significantly for both materials: COMP $(16.2 \pm 10.7 \mu \mathrm{m} / \mathrm{month})$ and LS2 $(5.5 \pm 3.3 \mu \mathrm{m} / \mathrm{month})$. Statistical comparison between wear time showed significant differences for both materials: COMP $p<0.037$ and LS2 $p<0.001$. A logarithmic fit (COMP $R^{2}=0.081$; LS2 $\left.R^{2}=0.038\right)$ of the data was calculated to estimate the wear progression.

Significance In patients with reconstructed VDO, restorations made of LS2 show a more stable wear behavior than ones out of experimental CAD/CAM composite. In cases of complete rehabilitation, load bearing CAD/CAM-composite restorations should be critically considered for application due to their occlusal wear behavior. However, when choosing a restorative material, not only the functional occlusal stability should be taken into account but also the prospect of minimally invasive treatment with maximum preservation of natural tooth structures.
\end{abstract}

Keywords Abrasion $\cdot$ Wear $\cdot$ Dental materials $\cdot$ CAD/CAM composite $\cdot$ Lithium disilicate $\cdot$ Wear behavior

\section{Introduction}

Tooth wear is a condition of growing concern these days. Loss of dental hard tissue has a multifactorial etiology. Basically,

Jan-Frederik Güth

jan_frederik.gueth@med.uni-muenchen.de

Kurt Erdelt

kurt.erdelt@med.uni-muenchen.de

Christine Keul

christine.keul@med.uni-muenchen.de

Gintare Burian

gintare.burian@med.uni-muenchen.de there are three main reasons which lead to worn dentition (erosion/bio corrosion, abrasion, and attrition), and previous studies showed that these wear mechanisms show mutual interactions $[1,2]$. Possible consequences of an accelerated loss of hard

Josef Schweiger

josef.schweiger@med.uni-muenchen.de

Daniel Edelhoff

daniel.edelhoff@med.uni-muenchen.de

1 Department of Prosthetic Dentistry, University Hospital, LMU Munich, Goethestrasse 70, 80336 Munich, Germany 
tissue can be a reduced vertical dimension of occlusion (VDO), an increased tooth sensitivity, and changes in esthetics and function. The rising prevalence and incidence of this complex condition forces dentists to develop new strategies for diagnosis, patient monitoring, and treatment in order to react as early and effectively as possible, using minimal invasive methods [3, 4].

$\mathrm{CAD} / \mathrm{CAM}$ polymers, also termed high-performance polymers (HPP), have been introduced to the market as an alternative to ceramics $[5,6]$. Polymerized following industrial standards and processed by subtractive methods using CAD/ CAM technology, the mechanical properties of these materials are considered to be superior to those of direct polymers [7]. However, the possible applications of $\mathrm{CAD} / \mathrm{CAM}$ polymers clearly depend on their individual chemical composition, as the individual parameters significantly influence their mechanical properties [8]. Today, these CAD/CAM polymers on the basis of highly cross-linked PMMA resins or filled composites are offered by numerous manufacturers. They attract interest in different fields in dentistry and allow numerous novel treatment options $[9,10]$.

Currently, CAD/CAM polymers on the basis on PMMA are used as long-term temporary restorations during extended pretreatment phases of up to 2 years [11]. Their material properties allow ultra-thin restoration designs, which dispense extensive tooth preparation and lead to significant dental hard tissue preservation $[12,13]$. However, the prospective transition to definitive ceramic restorations requires the clinician to prepare the teeth to ensure an adequate occlusal thickness and an appropriate edge design for the restorations [14]. Inevitably, this may lead to an additional loss of tooth structure.

Keeping this in mind, CAD/CAM polymers on the basis of highly filled composites might constitute a new definitive treatment approach without or with only minimal hard tissue loss. These polymers harbor favorable grinding/milling properties, and due to low modulus of elasticity, it results in higher edge stability, so that these polymers can be used in thinner designs than ceramic materials [10]. Some manufacturers have been offering similar materials for several years now and recommend their application as definitive restorations under clinical conditions. So far, no clinical data have been available on the longterm behavior of these restorations. The main limitation is that clinical research presents many challenges as patient recruitment, funding, and extended time to accumulate some reliable data on clinical restoration changes. Many different 3-D measuring techniques were used in the past, to provide quantitative data on dental materials wear $[15,16]$. These comparable methods were used in previous studies mostly reporting on the wear of single posterior composite crowns to be around $40 \mu \mathrm{m} /$ year $[17,18]$. The difference to the present study is that single crowns located within a tooth row were evaluated, but not a full arch reconstruction was conducted out of composite material. It can be assumed that in the previous studies the single crowns were protected by adjacent structures, which could result in comparable wear to adjacent structures. Whereas when a full mouth reconstruction is carried out, the wear behavior of the CAD/CAM polymers might be different especially if, as in the present study, they are to be used to maintain the reconstructed vertical dimension of occlusion (VDO).

The purpose of this clinical pilot study was (1) to present, apply, and evaluate a digital method for measuring wear in a clinical setting and (2) to assess the wear behavior of two restorative materials in patients with a reconstructed VDO after a generalized loss of tooth structure. In this study, an experimental $\mathrm{CAD} / \mathrm{CAM}$ composite was compared with a lithium disilicate ceramic regarding longitudinal abrasion characteristic over 2 years. The null hypothesis of the study was that the restorations made of the experimental $\mathrm{CAD} / \mathrm{CAM}$ composite exhibit similar wear rates as restorations made of lithium disilicate ceramic.

\section{Materials and methods}

\section{Patients}

The study was performed in accordance with the Code of Ethics of the World Medical Association (Declaration of Helsinki) after approval by the Ethics Committee of the university hospital of LMU Munich (012-12; 541-12).

A total of 12 (7 males, 5 females; mean age, $36.3 \pm$ 9.4 years) patients with changes in the vertical dimension of occlusion (VDO) due to loss of hard tissues were included in the study. In all patients, restoring the vertical dimension of occlusion with full arch antagonistic restorations in both jaws was indicated (no-prep occlusal veneers, partial crowns, or full crowns). Canine-guided occlusion through rehabilitation was achieved in every patient. The following inclusion criteria for study participation were defined:

- Age above 18 years and under 70 years.

- Appropriate, at least average oral hygiene.

- Extended decrease of the vertical dimension of occlusion (VDO) due to attritional, abrasive, erosive, or pathological damage to the tooth structure.

- Indication for a minimum of 12 restorations in antagonistic jaws.

- Healthy/treated periodontal tissues (at most grade 1 tooth mobility).

- Pregnant and breastfeeding women were excluded from the study.

All patients participating in the study were informed about the background of the study and the risks associated with it and gave their informed consent.

The patients were divided into two groups: 
1) Group COMP included 6 patients, who received adhesively bonded CAD/CAM restorations $(n=168)$ made of experimental, industrially polymerized composite blocks.

2) Group LS2 consisted of 6 patients, who received monolithic ceramic restorations $(n=168)$, as control group.

The wear rate was determined based on the first molar restorations (COMP $n=24$; LS2 $n=24$ ) in the maxilla and mandible. Measurements were performed after first and second year for each first molar which resulted in 96 post control datasets. An overview of the study process is shown in Fig. 1.

\section{Treatment and laboratory procedures}

The experimental composite material (Ivoclar Vivadent, Schaan, Liechtenstein) consisted of $22 \% V_{\mathrm{f}}$ matrix (dimethacrylate) and $78 \% V_{\mathrm{f}}$ filler (barium glass fillers, $15 \%$; ytterbium trifluoride, 9\%; mixed oxides, $44 \%$; silicon oxides, $3 \%$; copolymers, $7 \%$ ). The material used in this study exhibited the manufacturer's properties which were as follows: flexural strength $=167 \mathrm{MPa}$, modulus of elasticity $=11.4 \mathrm{GPa}$, Vickers hardness $=915 \mathrm{MPa}$, and water absorption after 7 days $=28 \mu \mathrm{g} / \mathrm{mm}^{3}$.

Mechanical properties of used lithium disilicate ceramic (IPS e.max Press, Ivoclar Vivadent, Schaan, Liechtenstein) according to manufacturer are as follows: flexural strength $=400$ $\pm 40 \mathrm{MPa}$, modulus of elasticity $=95 \pm 5 \mathrm{GPa}$, and Vickers hardness $=5900 \pm 100 \mathrm{MPa}$ (https://www.ivoclarvivadent. com/en/p/laboratory-professional/products/all-ceramics/ipsemax-technicians/ips-emax-press).

The clinical procedure in both groups was conducted corresponding to the state of the art in current adhesive (minimally invasive) restorations. Necessary core build-ups were made with direct low viscosity (Tetric EvoFlow, Ivoclar Vivadent,
Schaan, Liechtenstein) and/or high-viscosity composites (Tetric EvoCeram, Ivoclar Vivadent, Schaan, Liechtenstein) and a multi-step adhesive system (Syntac, Ivoclar Vivadent, Schaan, Liechtenstein). Impressions were taken with polyether (Permadyne/Impregum Penta, $3 \mathrm{M}$, Seefeld, Germany) by an individualized Rimlock tray. Fabrication of the restorations was completed in a dental laboratory by an experienced dental technician.

COMP restorations were designed and manufactured using the Cerec system (CEREC InLab V3.86, Dentsply Sirona, Bensheim, Germany), with the following settings: proximal contacts strength $=75 \mu \mathrm{m}$, occlusal contact strength $=25 \mu \mathrm{m}$, and adhesive gap $=20 \mu \mathrm{m}$. Before placing the composite restorations, the inner surfaces were prepared using modified Rocatec procedure (Rocatec soft $30 \mu \mathrm{m} ; 1$ bar; nozzle distance, $2 \mathrm{~cm}$; $5 \mathrm{~s}$ blast time per unit) and conditioned with Monobond Plus (Ivoclar Vivadent, Schaan, Liechtenstein).

LS2 restorations were fabricated using the press technique. The inner surfaces of the lithium disilicate restorations were etched with 5\% hydrofluoric acid (IPS Ceramic Etching Gel, Ivoclar Vivadent, Schaan, Liechtenstein) for $20 \mathrm{~s}$, rinsed with air/water spray for $60 \mathrm{~s}$, and cleaned in ultrasonic bath for next 60 s. Then, silan coupling agent as part of Monobond Plus (Ivoclar Vivadent, Schaan, Liechtenstein) was applied for $60 \mathrm{~s}$.

Adhesive bonding in both groups was performed with Total Etch \& Rinse technique using Syntac (Ivoclar Vivadent, Schaan, Liechtenstein) in combination with the Variolink II (Ivoclar Vivadent, Schaan, Liechtenstein) and light curing, following the manufacturer's instructions. If necessary, occlusal adjustments in static and dynamic occlusion were performed with ball-shaped diamond finishing bur (8801 314 018, Komet Dental, Lemgo, Germany) and water spray application. Finally, the adjusted occlusal areas were polished
Fig. 1 Overview of the study design and procedure

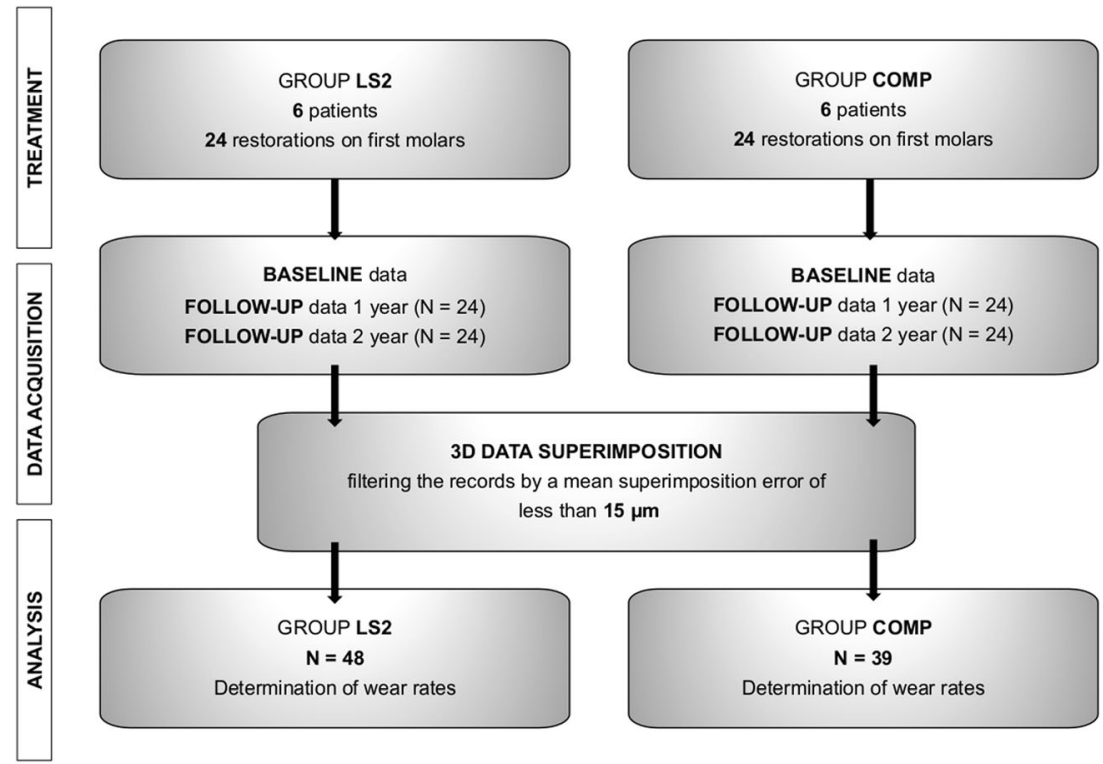


by adequate polishing sets (Composite: Set 4312A, Ceramic: 4313B, Komet Dental, Lemgo, Germany).

\section{Baseline and follow-up}

To investigate the wear behavior of the restorations in both groups, dental impressions with a polyether impression material (Impregum Penta, 3M Espe, Seefeld, Germany) were taken after adhesive bonding and occlusal adjustments of the restorations (baseline). The impressions were poured between 24 and $48 \mathrm{~h}$ with type IV dental stone (Plurastone, Pluradent, Offenbach, Germany). The resulting plaster casts were stored at room temperature $21^{\circ} \mathrm{C} \pm 1{ }^{\circ} \mathrm{C}$. All gypsum models were scanned with a laboratory scanner (D810, 3Shape, Copenhagen, Denmark). All follow-up recalls were performed by the same experienced clinician at approximate 12-month interval after clinical loading. Mean observation period in both groups was $371 \pm 106$ days (first year) and $769 \pm 102$ days (second year).

\section{Processing of datasets}

The resulting STL datasets at baseline and follow-up recalls were imported into the Geomagic Qualify 2012 surface matching analytical software (Geomagic Inc., Morrisville, NC, USA). As a first step, the individual restored first molars of the digital models were isolated and stored as separate datasets in order to facilitate a restoration-related analysis. The data points below the tooth equator were eliminated. Subsequently, the recall data were superimposed with the baseline data, initially highlighting the entire restauration surface of the reference dataset and the follow-up dataset using a best-fit method. The result of this overlay was visually evaluated and the average overlay error determined. Next best-fit alignment was conducted only over those surfaces in which the deviation was less than the overlay error. This procedure was iterated until the overlay error no longer decreased. Only datasets with an overlay error of less than $15 \mu \mathrm{m}$ were further processed (COMP $n=39$; L2S $n=48$ ). Figure 2 illustrates an example of the procedure. The error of the superimposition was documented for each specimen individually.
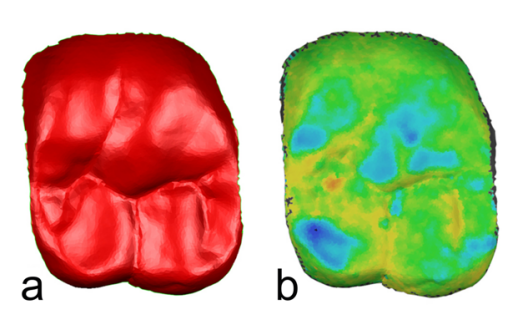

Fig. 2 Example of the iterative approach to the overlay of baseline and follow-up datasets: a overlay over the entire occlusal surface; b colorcoded representation of the differences between baseline and follow-up data after the first overlay; c exclusion of areas with antagonistic wear, to
This iterative approach allowed to delineate those areas of the restorations that showed signs of wear. After completion of the superimposition, the differences between the datasets were visualized by color-coded pictures which reproduced wear caused by the antagonist restoration. Only areas in which wear could be detected (blue color coding) were selected for further wear analysis. The distance data was exported and stored as individual result files (.csv). Figure 3 shows an example of the wear behavior based on color-coded representation.

\section{Wear evaluation}

The resulted files were imported into a statistics program SPSS (version 25, IBM, Armonk, NY, USA) and prepared for further analysis of wear. Subsequently, the average wear depth and the maximum wear depth were calculated perpendicular to the surface of the restoration. To ensure comparability of data in spite of different times in situ, wear was calculated by dividing the values by the number of wear days. Afterwards, the average wear rate per month and the average maximum wear rate per month were determined for the material groups. Furthermore, the data were analyzed for significant differences between the groups of materials (MannWhitney $U$ test). The $p$ value was set at 0.05 .

\section{Results}

\section{Superimposition error results}

A prerequisite for further analysis was a superimposition error between baseline and follow-up datasets less than $15 \mu \mathrm{m}$ after data overlay (Fig. 4). It turned out that the follow-up data for the experimental CAD/CAM composite caused larger superimposition errors in overlaying process than lithium disilicate. The group COMP exhibited a mean overlay error of $11.9 \pm$ $4 \mu \mathrm{m}$ after first-year follow-up, compared with $9.3 \pm 2 \mu \mathrm{m}$ in the group LS2. Furthermore, second-year follow-up datasets results confirmed increased superimposition errors in both groups. Group COMP showed an overlay error of $14.6 \pm$ 
Fig. 3 Color-coded representation of the abrasion behavior: a clinical photograph taken at baseline after restoration with lithium disilicate ceramics, $\mathbf{b}$ clinical photograph taken at the 24-month follow-up (worn surfaces were later marked in red), c color-coded representation of the deviations following data overlay, d clinical photograph at baseline after restoration with an experimental CAD/CAM composite, $\mathbf{e}$ clinical photograph taken at the 12-month follow-up (worn surfaces were later marked in red)
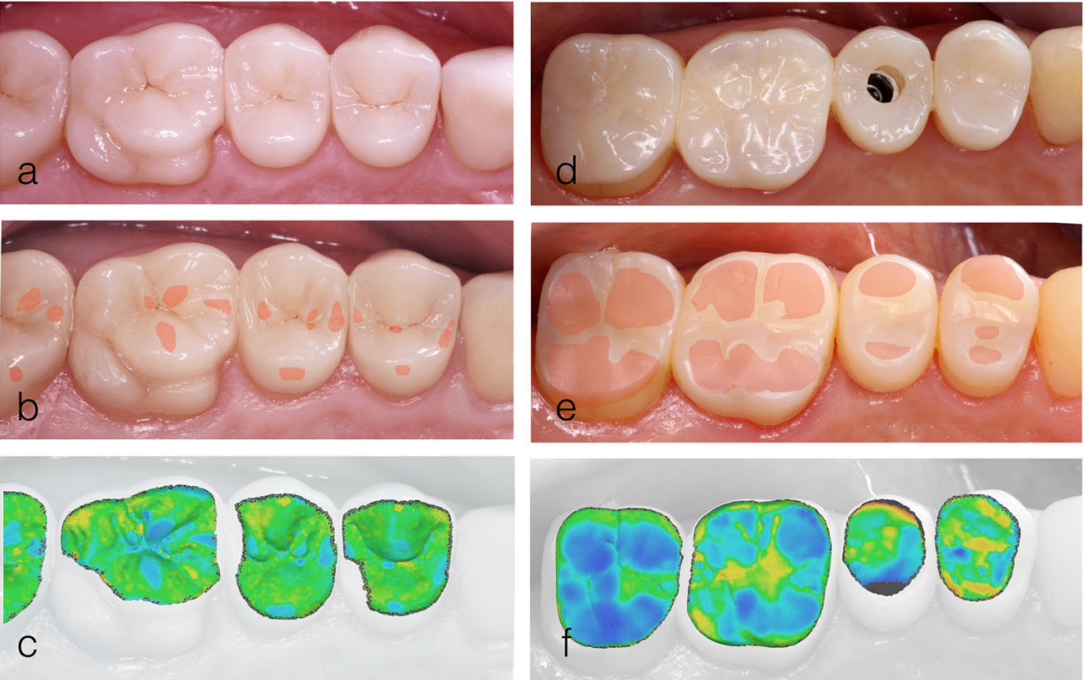

$7 \mu \mathrm{m}$, which was significantly higher in relation to first-year values. As a consequence, more datasets had to be excluded in second year. Group LS2 remained near constant with mean superimposition error of $9.4 \pm 1 \mu \mathrm{m}$. Filtering out the datasets with overlay errors less than $15 \mu \mathrm{m}$, the number of analyzed records was reduced to 39 in group COMP. All lithium disilicate ceramics fulfilled these criteria, and 48 records were included for further analysis.

\section{Average wear rates per month}

The values for the wear rates per month in first and second year after placement for COMP and L2S are shown in Table 1. Table 2 shows results of wear rates per year. The KolmogorovSmirnov test showed that no normal distribution of values was present; thus, the Mann-Whitney $U$ test was used for statistical comparison between materials and wear time.

Analyzing first-year data showed statistically significant differences $(p<0.001)$ between COMP $(24.8 \pm 13.3 \mu \mathrm{m} /$ month) and LS2 $(9.5 \pm 4.3 \mu \mathrm{m} /$ month $)$. Second-year data showed decreased wear rates per month for both materials, still with significant differences $(p<0.001)$ : COMP $(16.2 \pm$ $10.7 \mu \mathrm{m} / \mathrm{month})$ and $\operatorname{LS} 2(5.5 \pm 3.3 \mu \mathrm{m} / \mathrm{month})$. Statistical comparison of wear between first and second year showed significant differences for both materials: COMP $p<0.037$ and LS2 $p<0.001$. The results are shown in Fig. 5.

\section{Maximum wear rates per month}

The values for the maximum depth of wear per month in first and second year are shown in Table 3 and Fig. 6. The Kolmogorov-Smirnov test showed that no normal distribution of values was present; thus, the Mann-Whitney $U$ test was used for statistical comparison between materials and wear time. The average maximum wear rate across all restorations made of the experimental CAD/CAM composite was $76 \pm 42.9 \mu \mathrm{m} /$ month which was significantly different $(p<0.001)$ from the average maximum wear rates of $36.1 \pm 22.6 \mu \mathrm{m} /$ month for restorations made of lithium disilicate ceramics in first year. In second year, exhibited maximum wear rates decreased for both materials: COMP $45 \pm$ $23.3 \mu \mathrm{m} / \mathrm{month}$ and LS2 $19.9 \pm 14.3 \mu \mathrm{m} / \mathrm{month}$; these results still showed significant differences $(p<0.001)$. Figure 6 shows the corresponding box plots.
Fig. 4 Overlay error of each molar specimen in accordance with individual patients
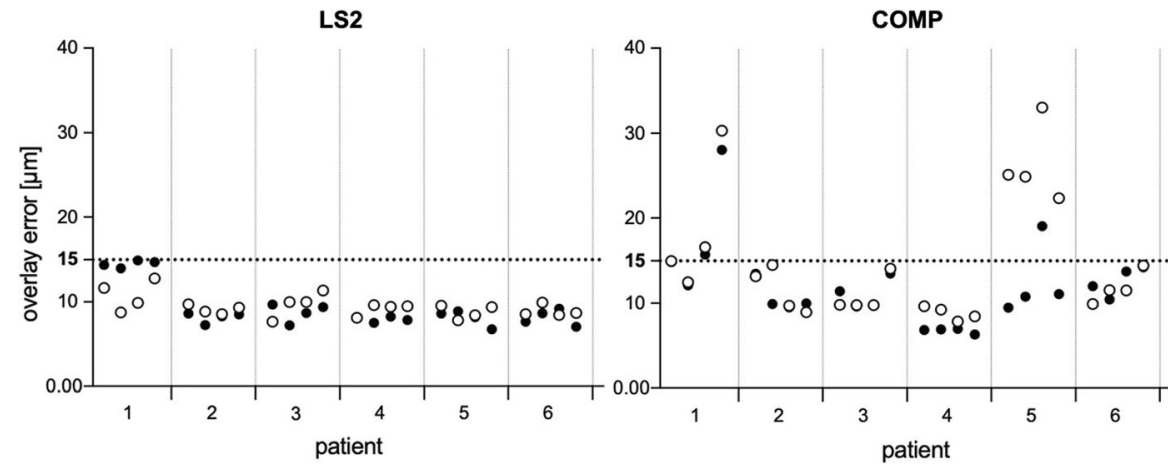

- 1 year

- 2 years 
Table 1 Average wear rates per month $[\mu \mathrm{m}]$

\begin{tabular}{lllllllr}
\hline & Time & N & Mean & SD & Median & 95\% CI & IQR \\
\hline LS2 & 1 year & 24 & 9.46 & 4.31 & 8.67 & $7.63 / 11.28$ & 4.56 \\
& 2 years & 24 & 5.47 & 3.29 & 4.44 & $4.08 / 6.86$ & 2.84 \\
COMP & 1 year & 21 & 24.76 & 13.32 & 24.92 & $18.69 / 30.82$ & 24.50 \\
& 2 years & 18 & 16.23 & 10.72 & 13.61 & $10.89 / 21.56$ & 12.97 \\
\hline
\end{tabular}

\section{Wear in time axis}

The progress of total wear over time for each specimen is shown in Fig. 7. The following graph demonstrates continuous increase of wear for both materials. Based on the previous statements, the statistically significant decrease of wear rates per month over time confirms that abrasion shows a time dependency. The highest overall loss of restorative material occurred during the first year of use, whereas between the first and second year, the amount of wear decreases. Curve fitting was calculated and adjusted with SPSS to analyze time dependence of wear.

Two assumptions were made for curve fitting: (1) At starting point, when restorations were placed, no wear had occurred yet. (2) The total wear increases with time. Based on these two assumptions, only linear and logarithmic functions are possible. However, a linear function does not fulfill assumption one, because it does not cross the $y$-axis at zero. Therefore, linear increase of wear rates must be rejected. Logarithmic function (COMP $R^{2}=0.081$; L2S $R^{2}=0.038$ ) showed the best fit to these data points, as the function starts almost at zero and increases continuously.

\section{Discussion}

The present clinical pilot study compared the wear behavior of antagonistic monolithic restorations made of two materials: experimental CAD/CAM composites and lithium disilicate ceramics. To our best knowledge, the present study is the first so far to compare wear of CAD/CAM composite versus CAD/ CAM composite with lithium disilicate versus lithium disilicate in vivo conditions [19]. The results showed significant differences in wear progress between these two materials in patients that received full mouth rehabilitation. Restorations

Table 2 Mean wear rates per year $[\mu \mathrm{m}]$

\begin{tabular}{lllrr}
\hline & Time & N & Mean & \multicolumn{1}{c}{ SD } \\
\hline LS2 & 1 year & 24 & 113.52 & 51.72 \\
& 2 years & 24 & 65.64 & 39.48 \\
COMP & 1 year & 21 & 297.12 & 159.84 \\
& 2 years & 18 & 194.76 & 128.64 \\
\hline
\end{tabular}

made of the experimental CAD/CAM composite exhibited higher wear rates than those made of lithium disilicate ceramics. The null hypothesis must therefore be rejected.

The average wear rates per month were higher in first year compared with the follow-up values in both groups. It should be taken into consideration that these wear rates will decrease every year as a possible consequence of the formation of the occlusion wear facets.

While the wear area increases, the applied forces are distributed onto a larger area. This reduces the forces per area and might the reason that wear rates are highest initially after placing the restorations, as restorations are adjusting to each other. Longitudinal studies are still needed to confirm our expectations on this wear behavior in vivo for extended follow-up intervals. As well, the possibility of non-contact area wear of composites, that is caused by failure of composite components, cannot be refused [20]. This might influence the accuracy of the superimposition and might even lead to higher overall wear in the composite group, which even more supports the findings of this study.

Quantitative wear measurement acquired in this study's clinical setting was assessed using a new iterative approach. Measurements were performed on entire occlusal surface on every first molar, using plaster casts after conventional impression. To minimize potential errors of this workflow, the overlay and analysis were performed for each molar individually, to gain a certain independence of adjacent structures. This made it possible to eliminate at least the influence of overall distortions of impressions and manufacture of plaster casts that could influence the results [21]. In addition, the superimposition process was iterated until the overlay error was no longer changed by further superimposition. In this way, the best fit of baseline and follow-up data over the areas that had not been exposed to any antagonistic wear could be achieved.

For the quantitative measurement of vertical height loss of antagonistic restorations, mean superimposition error of $15 \mu \mathrm{m}$ was determined as the standard deviation error between the data records. In vitro studies, the standard deviation of superimposition has been described to be between 5 and $10 \mu \mathrm{m}$ [22]. Against that data, capturing under clinical conditions seems to be more error prone and present higher variations; therefore, higher standard deviations up to $15 \mu \mathrm{m}$ had to be accepted. On the other side, data bellow tolerance of $15 \mu \mathrm{m}$ were excluded in this study to receive most reliable data. Based on individual bite forces and masticatory movements, every investigated specimen exhibited different pattern of abrasion. DeLong et.al reported that the estimation of superimposition for samples of clinical studies usually fluctuate from 10 to $20 \mu \mathrm{m}$ per point; they considered the superimposition of less than $10 \mu \mathrm{m}$ to be an excellent fit, whereas a value of more than $50 \mu \mathrm{m}$ indicates a poor fit [15]. This goes in line with other clinical investigations in measuring wear, where 
Fig. 5 Mean wear rates $(\mu \mathrm{m} /$ month). Boxplots illustrate median and IQR values. Circles represent the outliers

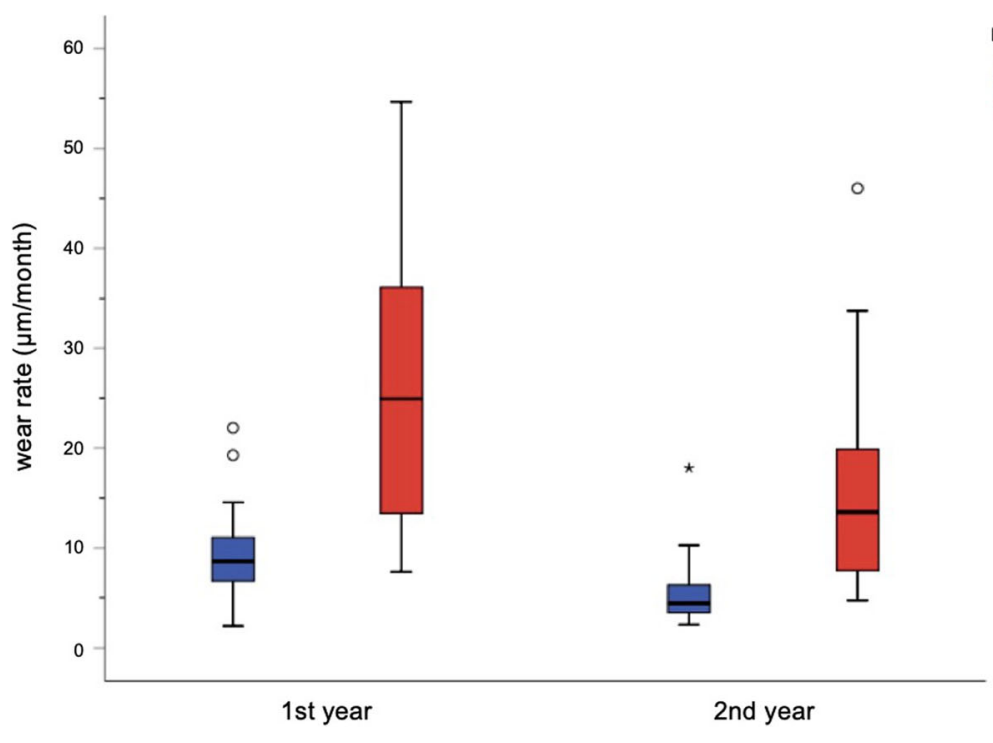

workflow inaccuracy in the range of 15-20 $\mu \mathrm{m}$ was considered acceptable [18, 23-26]. Schmid-Schwap et al. [27] even set the limit at $30 \mu \mathrm{m}$ for standard deviation/workflow inaccuracies for molars as reasonable, as they are more difficult to superimpose. However, this was stated for the wear of methacrylate artificial teeth. In presented study, composite restorations showed higher superimposition errors which may be caused by non-antagonistic wear which is more pronounced on composite than lithium disilicate ceramic [28].

Wear can be quantified using depth, area, and volume. The connection and correlation of these parameters are explained excellent by DeLong et al. [29]. However, the methodology of wear measurements under clinical conditions is currently intensively discussed [30-34]. In this clinical study, the parameter of vertical height loss measured perpendicular to working surface was applied. The calculation of volume changes under clinical conditions seems to be very error prone. Most critical point is to define area for volume calculation, between exposed and non-exposed area of wear. In contrast, the reproducibility and comparability of these measurements were restricted, due to high failure rate on assessing thin margins and different surface areas, what made this data unusable. Furthermore, previous studies already elucidated the advantage of measuring vertical height loss compared with

Table 3 Maximum wear rates per month $[\mu \mathrm{m}]$

\begin{tabular}{lllllllr}
\hline & Time & N & Mean & SD & Median & 95\% CI & IQR \\
\hline LS2 & 1 year & 24 & 36.13 & 22.55 & 31.99 & $26.61 / 45.65$ & 12.09 \\
& 2 years & 24 & 19.88 & 14.33 & 15.66 & $13.83 / 25.93$ & 7.24 \\
COMP & 1 year & 21 & 76.03 & 42.91 & 72.32 & $56.50 / 95.56$ & 58.37 \\
& 2 years & 18 & 45.06 & 23.27 & 38.86 & $33.49 / 56.63$ & 23.50 \\
\hline
\end{tabular}

volumetric wear measurement. The main advantage is the possibility of a direct quantification of wear and eliminating the influence of surface size [27, 31]. A combination of vertical height loss and surfaces measurement was desirable; however, surface measurement underlay the same trouble as volumetric measurements.

According to the biomimetics concept, the wear behavior of dental restorations should ideally resemble physiologic tooth enamel. However, clinical data on the wear behavior of natural teeth is rare and varies widely. In the few existing studies, the wear rates for natural enamel were found to be about 10-40 $\mu \mathrm{m} /$ year [35-37]. The parameter that was comparable with the measurements reported in the literature seems to be the mean wear rate per year. However, the results of clinical trials showed considerable fluctuations [30]. The wear rates differed significantly between different research groups; Etman et al. [38] stated wear of $148 \mu \mathrm{m}$ after first year for lithium disilicate glass-ceramic posterior crowns, whereas Kramer et al. [39] determined it as $78 \mu \mathrm{m}$ after 4 year for ceramic inlays made of lithium disilicate. Only very few studies investigated wear of posterior composite crowns in vivo and reported wear to be around $40 \mu \mathrm{m} /$ year, which is considerably lower than values found in this study [17, 18]. Although there is an abundance of clinical data on the wear characteristics of direct composite restorations, literature shows a considerable variation in results from 50 to $200 \mu \mathrm{m}$ per year [30, 40, 41]. It must be taken into account that these studies compared wear rates with opposing enamel as an antagonist. Besides that, direct composite resin restorations of class I/II are protected by enamel which limits the conclusions drawn in regard of biomechanical loading. Additionally, not only antagonistic situation but also the clinical environment in which the restorations are placed seems to play a role for wear rates, and it is clear that wear rates might differ for single restoration against different antagonists. In the present study, 
Fig. 6 Maximum wear rates $(\mu \mathrm{m} /$ month). Boxplots illustrate median and IQR values. Circles represent the outliers

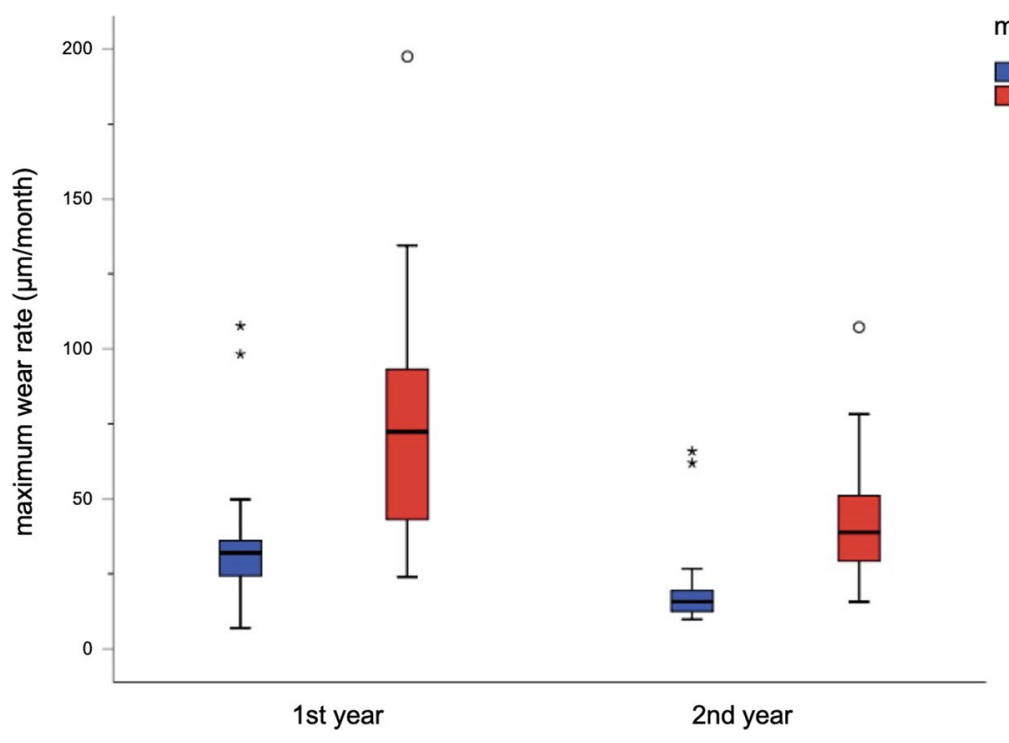

the patients received full mouth rehabilitation using either $\mathrm{CAD} / \mathrm{CAM}$ composite or lithium disilicate. In this clinical constellation, restorations are not protected by adjacent structures like enamel or crowns from other materials with lower wear rates. This means that the restorations in this study are subjected to complete bite forces and have to carry the full occlusal load either by opposing composite or ceramic. There is still no reliable data on wear rates in clinical cases of posterior restorations in cases of complete rehabilitation. Therefore, it is challenging to validate the credibility of our results. In this pilot study, wear was measured only on first molars. Further analysis applying the same methodology would also be considerable to make a distinction between premolars and molars, as some studies confirmed wear was more pronounced on molars than premolars [42, 43].

The analysis of the wear behavior of restorative materials and tooth structure in clinical cases poses two main problems for scientists and clinicians: taking exact and reproducible impressions and finding an adequate valid and reliable method for analysis of wear. Distortions or impression tolerances are two among other potential factors impairing the resulting cast quality [21, 44]. Moreover, the scanning process itself is prone to further inaccuracies, affecting the measurement results [45]. To avoid errors due to plaster cast fabrication, it is possible to scan impressions directly; however, undercuts and steep tooth geometries seem to limit this approach [46]. Also from the point of accuracy, there seems no significant advantage due to digitizing a conventional impression directly compared using the poured plaster model [47]. A considerable change of this step in the workflow would be the use of intraoral scanner for digital impressions. However, in vivo studies validated that conventional precision impression materials, like polyether used in this study, still show higher precision for full-dental arch impression compared with current intraoral scanners systems $[47,48]$. To exclude any influence of global distortion and inaccuracies of data acquisition, the present analysis is based on single tooth areas after sectioning the virtual dataset. Against this background, an application of intraoral scanner seems to be reasonable for further studies. Another limitation of the present pilot study was the relatively small cohort size. However, after an accumulated number of 87 numbers of datasets, significant differences between the groups of

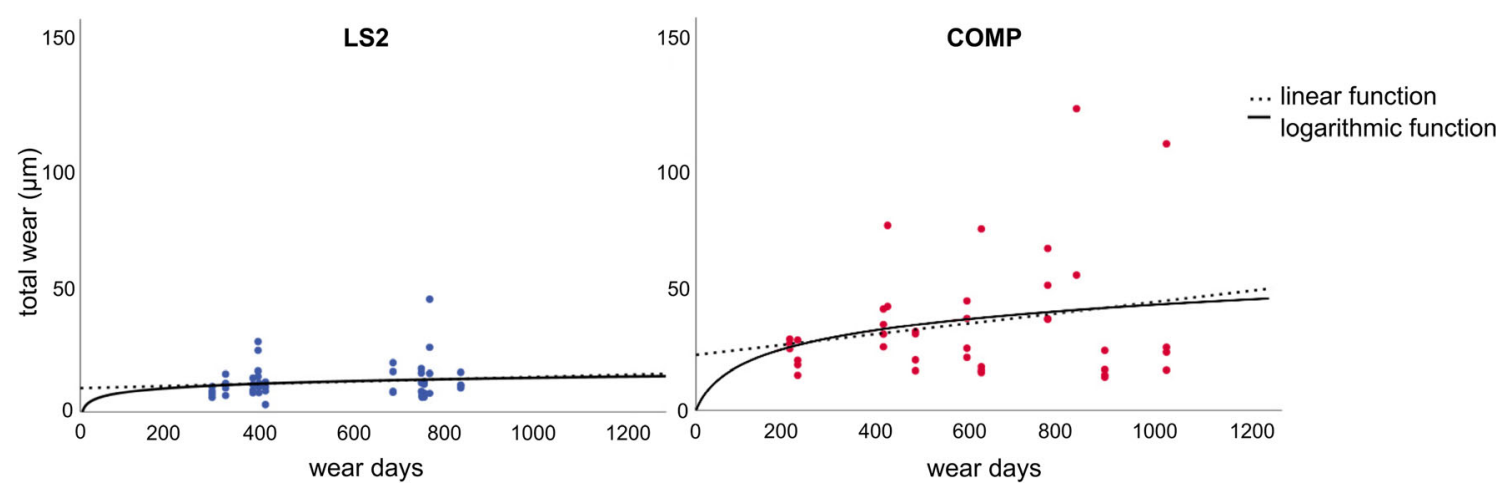

Fig. 7 Wear over time axis of each individual specimen 
materials could already be detected. Also, it can be presumed that our patients showed parafunctional behavior after altering the VDO, which could lead to increased wear of material during the first year. But so far, there is no evidence based on well-controlled clinical trials regarding this correlation [49]. However, based on the results for both types of restorations and assuming functionally active patients, an additional protective splint (night guard) may be recommended to be used at least overnight to prevent repeated early loss of vertical dimension.

To estimate the annual loss of vertical dimension, the average wear rates need be doubled because wear takes place in both jaws. Nevertheless, potential dental compensation has to be considered when this conclusion is drawn [50]. This would mean a total loss of height of $49.5 \mu \mathrm{m} /$ month in the posterior region for restorations made of the experimental $\mathrm{CAD} / \mathrm{CAM}$ composite and $18.9 \mu \mathrm{m} /$ month for restorations made of lithium disilicate ceramics in first year after placement. Based on the assumption of logarithmic wear model, this trend might be reduced over following years in function. However, this hypothesis has to be proven in further studies. Seen from this point of view, restorations made of lithium disilicate ceramic seem to offer a more stable prognosis in terms of wear and prevention in the long run.

On the other hand, $\mathrm{CAD} / \mathrm{CAM}$ composite restorations also have some advantages. These include the minimal invasiveness due to the better properties of CAD/CAM composite and higher flexibility of the material compared with ceramics [51]. The characteristics of the polymeric material and the superior edge stability facilitate procedures with very thin layers of the material and with little depth of preparation margins - or even without any preparation at all —which seems advantageous in terms of maximum tooth conservation. Moreover, CAD/CAM composite restorations have been associated with a more favorable wear behavior on the antagonistic enamel, which seen from a biomimetic point of view should be preferable as tooth structures will be preserved [52].

In summary, it can be concluded that in patients with a generalized loss of tooth substance, partial coverage restorations made of monolithic lithium disilicate ceramics to reconstruct the VDO showed lower wear rates than similar restorations made of an experimental CAD/CAM composite. Further studies are necessary to show whether these results are also valid for different clinical environments and settings, as well as for natural enamel antagonists.

\section{Conclusion}

Within the limitations of the present experiment, the following could be concluded. (1) COMP wore significant more than L2S $(16.2 \pm 10.7 \mu \mathrm{m} /$ month vs $5.5 \pm 3.3 \mu \mathrm{m} /$ month, $p=$ 0.001 ) after 2 years, and (2) wear versus time decreased following a logarithmic behavior. In cases of complete rehabilitation, load bearing CAD/CAM-composite restorations crowns should be critically considered for application due to their occlusal wear behavior.

Funding information Open Access funding provided by Projekt DEAL. The study was supported by a grant of Ivoclar Vivadent. The funding source had no influence in the collection, analysis, and interpretation of data, in writing the report, and the decision to submit the article for publication.

\section{Compliance with ethical standards}

Conflict of interest The authors Güth JF, Schweiger J, and Edelhoff D receive study grants and honoraria for scientific lectures from the sponsoring company. The authors Erdelt K, Burian G, and Keul CK declare no conflict of interest.

Ethical approval All procedures performed in studies involving human participants were in accordance with the ethical standards of the institutional and/or national research committee and with the 1964 Helsinki declaration and its later amendments or comparable ethical standards.

Informed consent Informed consent was obtained from all individual participants included in the study.

Open Access This article is licensed under a Creative Commons Attribution 4.0 International License, which permits use, sharing, adaptation, distribution and reproduction in any medium or format, as long as you give appropriate credit to the original author(s) and the source, provide a link to the Creative Commons licence, and indicate if changes were made. The images or other third party material in this article are included in the article's Creative Commons licence, unless indicated otherwise in a credit line to the material. If material is not included in the article's Creative Commons licence and your intended use is not permitted by statutory regulation or exceeds the permitted use, you will need to obtain permission directly from the copyright holder. To view a copy of this licence, visit http://creativecommons.org/licenses/by/4.0/.

\section{References}

1. Lussi A, Carvalho TS (2014) Erosive tooth wear: a multifactorial condition of growing concern and increasing knowledge. Monogr Oral Sci 25:1-15

2. Lussi A (2006) Dental erosion : from diagnosis to therapy. Monographs in oral science. Karger, Basel xii, 219 p

3. Loomans B, Opdam N, Attin T, Bartlett D, Edelhoff D, Frankenberger R, Benic G, Ramseyer S, Wetselaar P, Sterenborg B, Hickel R, Pallesen U, Mehta S, Banerji S, Lussi A, Wilson N (2017) Severe tooth wear: European consensus statement on management guidelines. J Adhes Dent 19(2):111-119

4. Wetselaar P, Lobbezoo F (2016) The tooth wear evaluation system: a modular clinical guideline for the diagnosis and management planning of worn dentitions. J Oral Rehabil 43(1):69-80

5. Magne P (2006) Composite resins and bonded porcelain: the postamalgam era? J Calif Dent Assoc 34(2):135-147

6. Güth JF et al (2012) Treatment concept with CAD/CAM-fabricated high-density polymer temporary restorations. J Esthet Restor Dent 24(5):310-318 
7. Mainjot AK, Dupont NM, Oudkerk JC, Dewael TY, Sadoun MJ (2016) From artisanal to CAD-CAM blocks: state of the art of indirect composites. J Dent Res 95(5):487-495

8. Stawarczyk B, Özcan M, Trottmann A, Schmutz F, Roos M, Hämmerle C (2013) Two-body wear rate of CAD/CAM resin blocks and their enamel antagonists. J Prosthet Dent 109(5):325-332

9. Güth JF et al (2016) CAD/CAM polymer vs direct composite resin core buildups for endodontically treated molars without ferrule. Oper Dent 41(1):53-63

10. Schlichting LH, Maia HP, Baratieri LN, Magne P (2011) Noveldesign ultra-thin $\mathrm{CAD} / \mathrm{CAM}$ composite resin and ceramic occlusal veneers for the treatment of severe dental erosion. J Prosthet Dent 105(4):217-226

11. Edelhoff D, Liebermann A, Beuer F, Stimmelmayr M, Güth JF (2016) Minimally invasive treatment options in fixed prosthodontics. Quintessence Int 47(3):207-216

12. Schlichting LH, Resende TH, Reis KR, Magne P (2016) Simplified treatment of severe dental erosion with ultrathin CAD-CAM composite occlusal veneers and anterior bilaminar veneers. J Prosthet Dent 116(4):474-482

13. Johnson AC, Versluis A, Tantbirojn D, Ahuja S (2014) Fracture strength of CAD/CAM composite and composite-ceramic occlusal veneers. J Prosthodont Res 58(2):107-114

14. Lawn BR, Pajares A, Zhang Y, Deng Y, Polack MA, Lloyd IK, Rekow ED, Thompson VP (2004) Materials design in the performance of all-ceramic crowns. Biomaterials 25(14):2885-2892

15. DeLong R, Pintado M, Douglas WH (1985) Measurement of change in surface contour by computer graphics. Dent Mater 1(1): 27-30

16. Mehl A, Gloger W, Kunzelmann KH, Hickel R (1997) A new optical 3-D device for the detection of wear. J Dent Res 76(11): 1799-1807

17. Ohlmann B et al (2008) Wear of posterior metal-free polymer crowns after 2 years. J Oral Rehabil 35(10):782-788

18. Zenthofer A et al (2013) Wear of metal-free resin composite crowns after three years in service. Dent Mater J 32(5):787-792

19. D'Arcangelo C, Vanini L, Rondoni GD, Vadini M, de Angelis F (2018) Wear evaluation of prosthetic materials opposing themselves. Oper Dent 43(1):38-50

20. Bayne SC, Taylor DF, Heymann HO (1992) Protection hypothesis for composite wear. Dent Mater 8(5):305-309

21. Christensen GJ (2008) The challenge to conventional impressions. J Am Dent Assoc 139(3):347-349

22. Heintze SD, Cavalleri A, Forjanic M, Zellweger G, Rousson V (2008) Wear of ceramic and antagonist-a systematic evaluation of influencing factors in vitro. Dent Mater 24(4):433-449

23. Soderholm KJ et al (2001) Clinical wear performance of eight experimental dental composites over three years determined by two measuring methods. Eur J Oral Sci 109(4):273-281

24. Rodriguez JM, Austin RS, Bartlett DW (2012) In vivo measurements of tooth wear over 12 months. Caries Res 46(1):9-15

25. Rodriguez JM, Austin RS, Bartlett DW (2012) A method to evaluate profilometric tooth wear measurements. Dent Mater 28(3):245-251

26. Palaniappan S, Bharadwaj D, Mattar DL, Peumans M, van Meerbeek B, Lambrechts P (2009) Three-year randomized clinical trial to evaluate the clinical performance and wear of a nanocomposite versus a hybrid composite. Dent Mater 25(11):1302-1314

27. Schmid-Schwap M, Rousson V, Vornwagner K, Heintze SD (2009) Wear of two artificial tooth materials in vivo: a 12-month pilot study. J Prosthet Dent 102(2):104-114

28. Mayworm CD, Camargo SS Jr, Bastian FL (2008) Influence of artificial saliva on abrasive wear and microhardness of dental composites filled with nanoparticles. J Dent 36(9):703-710

29. DeLong R (2006) Intra-oral restorative materials wear: rethinking the current approaches: how to measure wear. Dent Mater 22(8):702-711
30. Wulfman C, Koenig V, Mainjot AK (2018) Wear measurement of dental tissues and materials in clinical studies: a systematic review. Dent Mater 34(6):825-850

31. Stober T, Heuschmid N, Zellweger G, Rousson V, Rues S, Heintze SD (2014) Comparability of clinical wear measurements by optical 3D laser scanning in two different centers. Dent Mater 30(5):499-506

32. Lohbauer U, Reich S (2017) Antagonist wear of monolithic zirconia crowns after 2 years. Clin Oral Investig 21(4):1165-1172

33. Esquivel-Upshaw JF, Kim MJ, Hsu SM, Abdulhameed N, Jenkins R, Neal D, Ren F, Clark AE (2018) Randomized clinical study of wear of enamel antagonists against polished monolithic zirconia crowns. J Dent 68:19-27

34. Heintze SD, Reichl FX, Hickel R (2019) Wear of dental materials: clinical significance and laboratory wear simulation methods -a review. Dent Mater J 38(3):343-353

35. Lambrechts P, Braem M, Vuylsteke-Wauters M, Vanherle G (1989) Quantitative in vivo wear of human enamel. J Dent Res 68(12): 1752-1754

36. Molnar S, McKee JK, Molnar IM, Przybeck TR (1983) Tooth wear rates among contemporary Australian aborigines. J Dent Res 62(5): 562-565

37. Bartlett DW, Blunt L, Smith BG (1997) Measurement of tooth wear in patients with palatal erosion. Br Dent J 182(5):179-184

38. Etman MK, Woolford M, Dunne S (2008) Quantitative measurement of tooth and ceramic wear: in vivo study. Int J Prosthodont 21(3):245-252

39. Kramer $\mathrm{N}$ et al (2006) Antagonist enamel wears more than ceramic inlays. J Dent Res 85(12):1097-1100

40. Pesun IJ, Olson AK, Hodges JS, Anderson GC (2000) In vivo evaluation of the surface of posterior resin composite restorations: a pilot study. J Prosthet Dent 84(3):353-359

41. Palaniappan S, Elsen L, Lijnen I, Peumans M, van Meerbeek B, Lambrechts P (2010) Three-year randomised clinical trial to evaluate the clinical performance, quantitative and qualitative wear patterns of hybrid composite restorations. Clin Oral Investig 14(4): $441-458$

42. Mundhe K, Jain V, Pruthi G, Shah N (2015) Clinical study to evaluate the wear of natural enamel antagonist to zirconia and metal ceramic crowns. J Prosthet Dent 114(3):358-363

43. Loomans BAC, Kreulen CM, Huijs-Visser HECE, Sterenborg BAMM, Bronkhorst EM, Huysmans MCDNJM, Opdam NJM (2018) Clinical performance of full rehabilitations with direct composite in severe tooth wear patients: 3.5 years results. J Dent 70:97-103

44. Güth JF et al (2016) A new method for the evaluation of the accuracy of full-arch digital impressions in vitro. Clin Oral Investig 20(7):1487-1494

45. Gonzalez de Villaumbrosia P et al (2016) In vitro comparison of the accuracy (trueness and precision) of six extraoral dental scanners with different scanning technologies. J Prosthet Dent 116(4):543-550 e1

46. Bosniac P, Rehmann P, Wostmann B (2018) Comparison of an indirect impression scanning system and two direct intraoral scanning systems in vivo. Clin Oral Investig

47. Ender A, Attin T, Mehl A (2016) In vivo precision of conventional and digital methods of obtaining complete-arch dental impressions. J Prosthet Dent 115(3):313-320

48. Guth JF et al (2017) Accuracy of five intraoral scanners compared to indirect digitalization. Clin Oral Investig 21(5):1445-1455

49. Moreno-Hay I, Okeson JP (2015) Does altering the occlusal vertical dimension produce temporomandibular disorders? A literature review. J Oral Rehabil 42(11):875-882

50. Berry DC, Poole DF (1976) Attrition: possible mechanisms of compensation. J Oral Rehabil 3(3):201-206

51. Magne P, Schlichting LH, Maia HP, Baratieri LN (2010) In vitro fatigue resistance of CAD/CAM composite resin and ceramic posterior occlusal veneers. J Prosthet Dent 104(3):149-157 
52. Stawarczyk B, Liebermann A, Eichberger M, Güth JF (2015) Evaluation of mechanical and optical behavior of current esthetic dental restorative CAD/CAM composites. J Mech Behav Biomed Mater 55:1-11
Publisher's note Springer Nature remains neutral with regard to jurisdictional claims in published maps and institutional affiliations. 